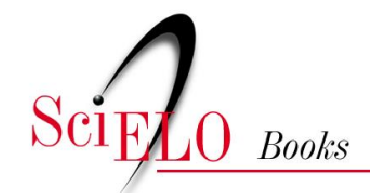

\title{
Ivan Ribeiro via prussiana, democracia política e reforma agrária
}

\author{
Raimundo Santos
}

SANTOS, R. Agraristas políticos brasileiros [online]. Rio de Janeiro: Centro Edelstein de Pesquisas Sociais, 2008. pp. 74-86. Ivan Ribeiro via prussiana, democracia política e reforma agrária. ISBN: 978-85-99662-81-6. Available from SciELO Books $<$ http://books.scielo.org $>$.

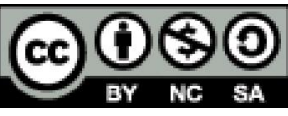

All the contents of this chapter, except where otherwise noted, is licensed under a Creative Commons Attribution-Non Commercial-ShareAlike 3.0 Unported.

Todo o conteúdo deste capítulo, exceto quando houver ressalva, é publicado sob a licença Creative Commons Atribuição Uso Não Comercial - Partilha nos Mesmos Termos 3.0 Não adaptada.

Todo el contenido de este capítulo, excepto donde se indique lo contrario, está bajo licencia de la licencia Creative Commons Reconocimento-NoComercial-CompartirIgual 3.0 Unported. 


\section{IVAN RIBEIRO \\ Via Prussiana, Democracia Política e Reforma Agrária ${ }^{61}$}

Ao reler ultimamente textos do campo intelectual Caio Prado Jr. PCB, temos realçado elementos discursivos que estimularam os comunistas a afirmar no país uma interpelação camponesa de tipo sindical. A Declaração de Março de 1958 já associara a reorientação na "tática agrária" comunista ao impulso que o associativismo começou a ter no mundo rural desde os inícios da década de 1950. Dois anos depois, no seu V Congresso, o PCB converteu sua experiência de "atuar nos sindicatos" - a diretriz com que abandonara o velho paralelismo sindical - na nova mediação dos grupos agrários: "A fim de impulsionar a organização das massas no campo, é necessário atribuir atenção primordial aos assalariados e semiassalariados agrícolas. Em virtude da sua condição social de proletários ou semiproletários, como também do seu grau de concentração, os assalariados rurais são mais suscetíveis de organizarem-se em sindicatos que podem constituir as bases iniciais para a mobilização das massas camponesas" (PCB, 1960: 72).

Esse tipo de atuação agrária não se deve apenas ao faro político e ao pragmatismo dos comunistas como também recebe certa influência de Caio Prado e tem em Alberto Passos Guimarães sua mais clara formulação. No entanto, se, por um lado, o argumento desenvolvido por Alberto Passos Guimarães lastreia a nova mediação camponesa, por outro, não tematiza a questão democrática no sentido do comentário que Sodré acrescentara ao seu livro de 1962. Com efeito, quase ao final de Formação histórica do Brasil, lê-se: "A defesa do regime democrático, no processo da revolução brasileira, não se prende, assim, ao supersticioso respeito a uma legalidade qualquer, mas na compreensão de que a democracia é o caminho apropriado ao seu desenvolvimento. Não interessa ao nosso povo, evidentemente, uma legalidade qualquer, mas o regime democrático efetivo cujo conteúdo esteja intimamente ligado ao desenvolvimento de alterações econômicas, políticas e sociais capazes de afetar profundamente o país e corresponder ao avanço

\footnotetext{
${ }^{61}$ Este registro sobre Ivan Ribeiro compõe o texto "Venturas e desventuras da revolução agrária no Brasil" (Relatório parcial da pesquisa "Pensamento social e agrarismo no Brasil, CPDA/ UFRRJ/Nead). Uma versão do mesmo foi publicado, sob o título "O agrarismo inconcluso de Ivan Ribeiro”, na revista Estudos Sociedade e Agricultura v. 14, n. 1, abril de 2006.
} 
das forças produtivas que impõem modificações radicais nas relações de produção" (Sodré, 1962: 404). (Os grifos são do autor destas notas).

No entanto, no contexto formulativo da passagem da década de 1950 aos anos sessenta, não se desenvolvera na publicística pecebista o tema da associação do agrário com a questão do formato do político, usando agora expressão de uma outra época (cf. Vianna, 1976). A passagem do livro de Sodré onde aparece alusão ao modo prussiano de nossa modernização é esta: "No campo, assim, de um lado estão os latifundiários ou latifundiáriocapitalistas; de outro, a grande massa de arrendatários pobres, o semiproletariado e o proletariado rural, toda a massa de camponeses pobres, ao lado dos camponeses médios e da burguesia rural, em luta pela posse da terra, mas sempre empurrada para engrossar o proletariado rural. As contradições entre as forças produtivas e as relações de produção chegaram a um ponto crucial. Elas nos fornecem a caracterização, do Brasil, segundo um estudioso, de um desenvolvimento à moda prussiana, sob a ação e a influência do imperialismo. Avança sem dúvida a penetração capitalista, mas os restos feudais vão sendo conservados e o monopólio da terra zelosamente defendido" (idem: 357).

Essa é a linhagem da qual descende Ivan Ribeiro. A ela Ribeiro incorpora circunstâncias discursivas que vivera intensamente durante quase duas décadas (1969-1987). Os primeiros dez anos correspondem ao tempo de um Brasil modernizado pela ditadura de 1964, que, nos anos de chumbo e na época dos exílios, levaria Ivan Ribeiro ao exterior. Também lhe resultou proveitoso ter conhecido o socialismo real na Polonia e vivido a via eleitoral ao socialismo no Chile de Salvador Allende. Ainda foi muito estimulante para Ivan Ribeiro sua passagem pela Itália, antes de retornar ao Brasil, no tempo do PCI de Berlinguer e do "compromisso histórico". Esta última experiência consolidou seu vínculo com a obra de Gramsci, autor da sua preferência, conhecido no convívio com velhos e jovens intelectuais do seu PCB, partido ao qual se manteve intelectualmente ligado até morrer, em 8 de setembro de 1987, no acidente de avião que vitimou o ministro Marcos Freire e membros da sua equipe, da qual Ribeiro fazia parte.

$\mathrm{Na}$ sua militância, essas circunstâncias se cruzariam no que poderíamos chamar - em referência ao debate que antecedeu a Declaração de Março - de segunda renovação pecebista (Santos, 1992; 1994). Ele integrou uma corrente que, ainda no exílio, desde 1975, procuraria uma convergência - buscando uma segunda "nova política" - entre o sentido da tática de frente democrática, de construção progressiva e capaz de resistir, isolar e, afinal, derrotar a ditadura, arduamente defendida pelo PCB, e o renovamento do marxismo político brasileiro tentado por outros intelectuais da sua geração naqueles tempos eurocomunistas.

Como se sabe, derrotada essa corrente no interior do PCB, no VII Congresso de 1982-83, alguns deles lançaram a revista Presença, que circularia por todo o decênio subsequente. Pode-se encontrar registro público dessa última fase militante de Ivan Ribeiro em artigos seus publicados no Jornal da República, que circulou em São Paulo durante o ano de 1979, no qual Leandro Konder escrevia - e para onde levou companheiros seus daquele grupo intelectual pecebista. Há textos de Ivan Ribeiro no semanário comunista Voz da Unidade publicados em 1981 e depois na revista Presença, da qual, aliás, ele próprio era um dos principais animadores, junto com Luiz Werneck Vianna, Carlos Nelson Coutinho e Leandro Konder.

\section{Um novo clima intelectual no campo pecebista}

A menção ao prussianismo e às modalidades farmer e alemã de evolução agrária já não era nova no $\mathrm{PCB}$, tendo circulado nos debates do $\mathrm{V}$ Congresso do PCB de 1960. Todavia, essas categorias produziriam outros resultados no PCB quando, na ensaística da corrente anteriormente citada, passou-se a realçar justamente a associação que - em sua reflexão sobre a revolução burguesa não clássica - Lênin fazia entre o problema agrário e a forma do político. A hipótese prussiana tem novo aproveitamento quando os citados jovens publicistas brasileiros tentaram apreender aquele tipo de associação numa experiência de capitalismo tardio e dependente, procurando trazer esta problematização para a práxis política de esquerda.

Como dizia um deles, aqui não tivemos um curso burguês clássico, tendo o país conhecido uma "estruturação prussiana", cuja singularidade "estaria no fato do setor agrário mais desenvolvido em termos capitalistas o agroexportador - ter sido desalojado do poder pelo menos desenvolvido" (Viana, 1976). ${ }^{62} \mathrm{E}$ ainda: "Na situação do campo brasileiro, a ausência de

${ }^{62} \mathrm{O}$ argumento prosseguia: "Isso se explica, como vimos, pela impossibilidade daquele setor em dirigir o processo de modernização dado o seu isolamento real e incontornável das 
um campesinato dinâmico, resultante da sua falta de vínculo com a sociedade mercantil, barraria um processo de transformações agrárias 'à americana'. Basicamente, a questão se resolvera pela assunção de papéis capitalistas pelo grande proprietário de terras, exportador ou não". (Idem: 133). O país se modernizara sob os auspícios da política, a burguesia crescera e expandira o seu domínio sem postular hegemonia social e política, sempre amparada pelo Estado, "fazendo dele seu partido político real". Ao manter sua aliança com as oligarquias agrárias atrasadas e ao ter se realizado como classe sem haver dirigido um processo revolucionário, aquela burguesia se tornava incapaz de liderar a democratização da sociedade (Vianna, op. cit.).

Em relação ao tempo contemporâneo, a referida ensaística chamava a atenção para o caráter não recessivo do novo regime que emergira da derrubada de Goulart e modernizara de modo conservador tanto a economia como a própria agropecuária (Vianna, 1983; Coutinho, 1986). Argumentava-se nessa literatura pecebista que, na circunstância do pós-64, o dado estratégico viria a ser a relação entre o intenso crescimento das forças produtivas nacionais e a natureza da transição democrática em pleno curso no final da década de 1970, sob impulso da lógica econômica modernizante mas dependente do oportuno desempenho dos atores políticos (Vianna, 1983).

Nessa construção tornava-se crucial o tema da complementaridade entre "transição política" e "revolução", trazendo-se até nós a bibliografia que realçava o caso daqueles países que haviam se modernizado tardiamente por vias autoritárias, sem ter criado uma institucionalidade política adequada (idem). As experiências de lá e a de cá sugeriam que, à hora do colapso dos seus regimes autoritários, poder-se-ia formar aqui uma situação na qual a democratização política do país, então cada vez mais em rápido andamento, não só viria concluir o período ditatorial como também poderia trazer - dizia outro daqueles intelectuais - "consequências progressistas de efeito quase revolucionário” (Konder, 1984).

demais classes, camadas e estratos sociais em emergência na sociedade civil. Mas o domínio do aparelho do Estado por parte dessa elite 'atrasada' no econômico lhe vai facultar um percurso extremamente rápido no sentido da adoção de novos papéis econômicos, como o do empresário agrícola, do industrial ou do financista" (idem: 139).
No plano da "formulação da política", esse clima intelectual representou, no $\mathrm{PCB}$, um novo passo a redimensionar a proposição da Declaração de Março, a qual já em 1958 havia rompido com o viés estagnacionista, passando a associar ao crescimento econômico um processo de complexificação social e a tendência do país à democratização política. Ao comparar a nossa via de modernização com o modelo clássico de revolução burguesa, aquela ensaística advertia que, aqui, a relação entre economia e política obedecia a uma lógica de natureza "muito mais irregular", também se podendo imaginar nossa modernização burguesa como uma "revolução passiva".

Essa qualificação, sobremaneira após se apreender a nova circunstância do pós-64 como uma contrarrevolução modernizadora, ${ }^{63}$ levava a se ter uma ideia de mudança social diferenciada do antigo axioma atraso/revolução. Daí se tendia a conceber o processo mudancista como uma gramsciana "guerra de posições", no dizer de Carlos Nelson Coutinho; ou, ainda, como um processo de transformações duradouras que assumiria forma de "reformismo forte" à medida que a democratização política, intensa desde a anistia de 1979, se aprofundasse cada vez mais.

Assim ampliado a partir de meados da década de 1970, esse marxismo político implicaria um outro modo de colocar o problema agrário, como se pode ver justamente na ensaística de Ivan Ribeiro, publicista que justamente emerge, na acima chamada segunda renovação pecebista, como autor especializado no tema rural. Em vez de limitar-se à centralidade da aliança operário-camponesa, continuando o modelo marxista e leninista de revolução, a nova leitura da questão agrária - e rural - viria conceder cada vez mais importância estratégica à relação entre a democratização social e o enraizamento progressivo da democracia política em toda a formação social; uma relação que só se assentaria com o concurso do campo da política.

A nova percepção seguiria a trilha aberta por Caio Prado Jr. com sua insistência no sindicalismo generalizável no território e Alberto Passos Guimarães, autor que condicionava o tema camponês à política geral de ${ }^{63}$ Carlos Nelson Coutinho relembra o conceito de "fascismo pelo alto" de Barrington Moore
para referir-se ao que ele chama de "paradoxo aparente" de um regime
"contrarrevolucionário" que, como no caso do Japão pré-bélico do exemplo de Moore, aqui
também se colocava à frente de um processo de intensificação do desenvolvimento das forças produtivas (Coutinho, 1986). 
frente única. Afastando-se da sociologia clássica das revoluções, a nova percepção iria sugerir que os camponeses fossem interpelados como uma questão relativa à condição de exclusão da "maioria da população" (no sentido do autor desta última expressão, Caio Prado Jr.) e, agora decididamente, sob o ponto de vista da "generalidade da política". Vale dizer, como grupos que, ao invés de objeto de instrumentalização a serviço de operações de poder - mesmo que chamados para projetos emancipatórios futuros -, deviam ser vistos como contingentes a se incorporar à economia realmente existente no país, à vida nacional, em particular ao seu sistema político democratizado.

Ivan Ribeiro não chegou a consolidar propriamente um constructo agrarista, mas deixou sugestões para uma visão renovada da reforma do mundo rural brasileiro em moldes democrático-institucionais. Seu recurso à via prussiana tem esse sentido ao fazer parte do contexto discursivo em que o conceito voltava a circular no PCB. No grupo intelectual a que pertencia Ribeiro a noção de via prussiana era relançada tanto para servir como cânone de interpretação do nosso capitalismo quanto como cânone de análise política. Neste caso, como um recurso útil para divisar com maior definição a problemática geral posta aos comunistas naquela fase final do PCB: a democratização da vida nacional requerida pelo padrão histórico da modernização "pelo alto" como uma transformação de caráter prolongado (falava-se naqueles tempos da anistia de 1979 em reversão do prussianismo). Este era o tema em torno do qual, na época, discutia-se o caminho democrático brasileiro ao socialismo.

\section{Uma reforma agrária sob procedimentos democráticos}

Em vez de ver na modernização da agropecuária brasileira o cancelamento da reforma agrária, Ivan Ribeiro vai mostrar que a nova circunstância redimensionava o problema agrário e exigia outro tipo de reformismo. Diversamente de Caio Prado Jr. e Alberto Passos Guimarães que, mesmo no pós-64, mantiveram suas reservas ante o crescimento do nosso capitalismo, Ribeiro não se fecharia ante o tema da modernização, mas daria um passo a mais na consolidação da ideia de reforma agrária "ampliada". Para este conceito já apontavam alguns autores, como o próprio Caio Prado Jr. e particularmente Ignácio Rangel. Com argumentos diversos, os clássicos sugeriam um reformismo que ao problema fundiário combinasse outras dimensões da questão agrária e rural, como a legislação social, no caso do historiador comunista; ou os problemas "impropriamente agrários", como propunha Rangel em 1962, atento à associação entre reforma agrária e excedente populacional. ${ }^{64}$

Ivan Ribeiro expõe o seu argumento no texto "A agricultura e o capitalismo no Brasil", publicado originariamente em 1975, com o pseudônimo de Cláudio Barros, na revista Études Brasiliennes, editada pelo PCB em Paris na época de exílio dos anos de chumbo. Ribeiro procurava mostrar que a agricultura brasileira já deixara de ser o lócus dos setores mais atrasados da economia, modernizada por um capitalismo agrário sob a égide da grande propriedade. Ao modo prussiano, um conjunto de transformações foi adaptando nossa agricultura, substituindo procedimentos "feudais" por procedimentos burgueses, constituindo um mundo onde "misérias modernas" coexistiam com "misérias antigas" (Ribeiro, 1975; 1988). ${ }^{65}$ Ao recorrer à chave do prussianismo, Ribeiro tanto reconstruía teses do seu próprio partido, que ainda alimentavam a ideia de reforma agrária antifeudal e antilatifundiária, como interpelava visões que convocavam ações camponesas dissidentes da ordem institucional e que ainda naqueles anos resistiam em aceitar o reformismo agrário brasileiro. Um reformismo que, há décadas, passara a tematizar constrangimentos de tipo sistêmico (há muito tempo, era tema seu a incorporação dos camponeses à economia realmente existente no país) e a valorizar as possibilidades de ampliação da cidadania no mundo rural. Aliás, como defendiam, desde os anos 1950, o Iseb, o próprio PCB e áreas de grandes partidos, como o PTB de Jango; e, depois de 1964, não

\footnotetext{
${ }^{64}$ As razões de Caio Prado Jr. advinham da sua teoria sobre a natureza da formação social; no caso do argumento de Rangel, a concentração nos aspectos "impropriamente agrários" (problemas agrícolas, relativos a produção e preços, especialmente os canais de intermediação, cf. Silva, 1996; 1998) devia-se à inexistência no pré-64 de condições políticas para um vasto processo expropriatório. José Graziano da Silva, na época do primeiro governo de Fernando Henrique, retomaria aquela conexão de Rangel para propor uma nova reforma agrária "não essencialmente agrícola", ampliando o conceito (“... é preciso criar novas formas de ocupação para uma parte significativa da população brasileira que não tem qualquer qualificação profissional que os habilite a procurar outra forma de inserção produtiva no novo mundo do trabalho que se delineia já para este final de século", cf. Silva, op. cit.: 82).

${ }^{65}$ Ribeiro faz sua aquela conhecida expressão de Marx, também citada por H. K. Takahashi, economista japonês com quem, no seu ensaio, Ribeiro dialogava a propósito do tema da via prussiana na transição do feudalismo ao capitalismo (idem).
} 
poucos ambientes de extração pluriclassista que convergiam na resistência democrática ao regime militar.

Sem alimentar nenhuma forma de campesinismo reativo à modernização, Ivan Ribeiro destacava da sua leitura do mundo rural que emergia na década de 1970 os grandes setores da agricultura, em que, dizia ele, não se justificava o parcelamento da propriedade e a criação de uma economia camponesa e em que se deveria trabalhar para a ampliação e melhora das condições de trabalho, universalizar a legislação trabalhista e enraizar um largo e diversificado associativismo (Ribeiro, op. cit.), nisso recordando Caio Prado Jr. O que não implicava menosprezar a economia familiar camponesa, à qual, por não ser ainda completamente capitalista, Ribeiro achava que um processo de reforma agrária farmer poderia trazer grandes benefícios e representar avanço considerável para vastos contingentes sociais (idem). Ademais, Ivan Ribeiro se mantinha atento ao processo da "modernização excludente" que provocava a diferenciação "para baixo", com a dissolução das pequenas propriedades e a transformação dos camponeses sem trabalhadores volantes e assalariados nos pequenos centros urbanos regionais, num contexto de fragmentação social; processo que logo seria investigado pela bibliografia especializada daquele começo da década de 1980. Ele percebia ainda que se os camponeses perdiam a sua definição econômico-revolucionária e que "eles" adquiriam nos (ou em interação com os) grupos sucedâneos um protagonismo novo, gerando outros tipos de processos sociopolíticos que convergiam com a secularização que a expansão da mídia provocava no mundo rural erodindo a ordem de mando oligárquica da sociedade agrária (Ribeiro, 1983). Em suma, neste registro de Ivan Ribeiro, que permanecerá inconcluso no campo comunista, o destino do mundo rural era visto - sob olhar inspirado na melhor tradição marxista - como capaz de renovar-se em moldes modernos. Ao contrário de alimentar a ideia de que a modernização só lhe traria catástrofes, essa ensaística ensejava a ideia de que o mundo rural não tinha porque não se conciliar com a esfera econômico-social, com a democracia política e a cultura, como as cidades vinham fazendo há muitíssimo tempo, não obstante as patologias que mais e mais se acumulavam em amplas franjas do seu mundo ao mesmo tempo modernista e devastado por novas mazelas.

Com atualizada percepção de renovamento do país, Ivan Ribeiro redimensionava sua tradição, como, por exemplo, quanto ao conceito de democracia, compreendida, em relação ao mundo rural, de modo ambíguo, mais como incorporação econômico-social dos camponeses. Em sua ideia de reforma agrária "ampliada", concebida no contexto de nossa modernização "pelo alto", Ribeiro não realçava apenas as esferas da inclusão social e da revitalização econômica, mas sublinhava uma dimensão de enlace do mundo rural com a questão democrática em geral. Dir-se-ia que, neste ponto, o autor buscava um enfoque alternativo que deslocasse a problemática da reforma agrária do "estrutural" para o âmbito do “institucional”. Ou seja, Ribeiro não só mobilizava sua tradição - à qual, desde meados dos anos 1950, procurava equacionar politicamente o tema agrário - como pretendia apontar processos que tornariam possível aos camponeses e trabalhadores rurais "entrar no jogo político enquanto força de classe e individualidade" (idem); vale dizer, levá-los para dentro de um sistema político democratizado.

As outras circunstâncias vividas pelo publicista também deixaram traços na sua passagem pela academia brasileira. Primeiramente se juntou ao grupo de pesquisadores que se havia reunido, em meados dos anos 1970, em torno do tema agrário no centro acadêmico da FGV conhecido como a pós-graduação do Horto Florestal ou CPDA (Curso de Pós-graduação em Desenvolvimento e Agricultura). Ele também esteve na transferência do mesmo CPDA para a Universidade Rural, em 1984, onde, juntamente com outros professores militou na política universitária ativando - inclusive como candidato - as movimentações das primeiras eleições diretas para Reitor. Não é um acaso que a vivência no socialismo real e no Chile de Allende se faça presente nos textos que Ribeiro escreveu sobre o tema rural, ajudando-o a problematizar uma das questões da sua preocupação acadêmica: a agricultura familiar. Este tema, segundo ele, era ainda pouco estudado no Brasil da segunda metade dos anos 1970. Da vivência no socialismo da Polônia e do diálogo com o economista polonês Jerzi Tepicht, Ivan Ribeiro trouxe a questão da persistência da pequena produção familiar nos processos de reestruturação da agricultura. Questão que igualmente veio da via chilena ao socialismo, experimento conturbado por condutas equivocadas quanto à expropriação das pequenas e médias unidades produtivas. Pode-se dizer que ambas experiências instigaram Ribeiro a realçar o tema da função dos pequenos produtores na reforma do mundo rural brasileiro. 
A propósito disso, recorde-se que, em um de seus artigos publicados no Jornal da República, de 1979, Leandro Konder chama a atenção para o fato de que, dentre os autores que àquela época mobilizavam o conceito leniniano de via prussiana, já estava Ivan Ribeiro, por conta do seu texto chamado "A importância da exploração familiar camponesa na América Latina", que fora publicado na revista de São Paulo Temas de Ciências Humanas, em 1978 (Konder, 1979; 1980).

Com efeito, nesse ensaio há a postulação apontada por Konder: "As particularidades da América Latina - diz Ribeiro em 1977 - adquirem maior nitidez quando observamos a circunstância de que, no Continente, a evolução do capitalismo na agricultura (com exceção do México) seguiu um caminho aproximado da via prussiana. Isso significa que os latifúndios subsistem e se convertem paulatinamente em base da exploração capitalista da terra; conservam-se, igualmente, durante décadas, seu predomínio político, a opressão, a humilhação, a miséria e a ignorância dos camponeses. Não ocorreram revoluções burguesas do tipo clássico, através das quais a grande propriedade fosse destruída radicalmente (e, com ela, os traços pré-capitalistas), abrindo-se assim caminho para o livre desenvolvimento do capitalismo com base em propriedades familiares." (Ribeiro, 1977; 1988: 162). Completemos essa passagem: "Como resultado, o que é definido na América Latina como exploração familiar camponesa resulta de um conceito mais elástico, englobando unidades produtivas cuja força de trabalho é obrigada a procurar ocupação fora dos limites de sua parcela e abrangendo arrendatários que cultivam as terras alugadas basicamente com sua mão de obra familiar. Entretanto mantém traços comuns com a economia camponesa europeia, tais como a utilização intensiva da força de trabalho no cultivo das terras e a baixa absorção de insumos industriais externos" (idem: 162-63). Naturalmente essa generalização da hipótese prussiana para o Continente depreende-se do caso brasileiro por sermos o país, como esclarecia então o próprio autor, "em que se faz sentir com mais força a versão latino-americana da via prussiana de transição ao capitalismo" (idem: 166).

O destaque dado por Ivan Ribeiro às explorações familiares camponesas não era apenas uma "concessão" a seres que estariam condenados ao desaparecimento e à socialização conforme a clássica previsão marxista, mas decorria das "significativas qualidades" que ele reconhecia na economia camponesa. ${ }^{66}$ Como registrava o autor, a valorização decorria de duas posturas: de um lado, a de não se considerar os assalariados típicos e os super-minifundistas como os únicos grupos "capazes de apoiar o processo de transformação na agricultura" e, de outro, o cuidado de evitar o menosprezo dos agricultores familiares que levava "ao estreitamente da base política necessária ao bom êxito das reformas estruturais" (idem). No entanto, esse realce nas explorações familiares camponesas não portava conotação campesinista, ou seja, não implicava "negar a substancial importância de uma ação simultânea em relação ao setor capitalista da agricultura", como ele próprio anota, retomando o argumento geral nas últimas linhas do seu ensaio (idem: 175).

Com essa trajetória, não estranha que, com o advento da Nova República, Ivan Ribeiro se licenciasse do CPDA para integrar a equipe do ministro Marcos Freire, motivado pelo que ele mesmo à época dizia ser um combate para afirmar uma linha mais reformista na área agrária do primeiro governo civil na redemocratização da segunda metade dos anos $1980 .{ }^{67}$ Ivan Ribeiro interrompeu seu labor publicista ainda jovem, deixando incompletas pesquisas acadêmicas sobre o tema rural. Sua presença, todavia, pode ser visualizada nos textos recolhidos pela coletânea organizada por Carlos Nelson Coutinho e Maria Beatriz David de Albuquerque, chamada Agricultura, Democracia e Socialismo, publicada em 1988 pela editora Paz e Terra, pouco menos de um ano após a sua morte.

\begin{abstract}
${ }^{66}$ Ribeiro enumerava: fonte de emprego e de aumento da produção com técnicas não modernas (poupando assim insumos industriais), "não podendo, porém, ser consideradas como grande potencial de acumulação de capital" (idem: 165).

${ }^{67}$ Uma semana antes do acidente de avião, encontrei-me com Ivan Ribeiro na Rodoviária de João Pessoa, ele vindo de Petrolina (PE) onde fora cumprir missão de pesquisa e eu proveniente de Campina Grande (PB) onde então residia. Ribeiro me relatou na ocasião que, devido à ambigüidade da Nova República, naquele momento estava demissionário da equipe da reforma agrária do governo. No entanto, ainda esperaria uma reunião do ministro Marcos Freire com o presidente Sarney, agendada para os próximos dias daquele mês de agosto de 1987, da qual ele esperava definição quanto aos rumos imediatos do Ministério da Reforma Agrária.
\end{abstract}




\section{Referências bibliográficas}

COUTINHO, Carlos Nelson. As categorias de Gramsci e a realidade brasileira. Presença, n. 8, ago. 1986.

KONDER, Leandro. "Via prussiana" (1979). In: Os comunistas e a democracia no Brasil. Rio de Janeiro: Graal, 1980.

O atraso é tanto que o governo Tancredo terá efeito quase revolucionário. Tribuna da Imprensa, 24 de setembro de 1984.

PCB. Declaração do Comitê Central sobre a Política do PCB (1958). In: Vinte Anos de Política. São Paulo: Lech, 1980. 1960.

Teses para discussão do V Congresso, folheto, Rio de Janeiro,

RANGEL, Ignacio. A questão agrária brasileira. Recife: Comissão de Desenvolvimento Econômico de Pernambuco, 1962.

RIBEIRO, Ivan de Otero. A agricultura e o capitalismo no Brasil (1975). In: Coutinho, Carlos Nelson e Albuquerque, Beatriz D. de (orgs.). Agricultura, democracia e socialismo. Rio de Janeiro: Paz e Terra, 1988.

. A questão agrária e a democracia. Presença, n. 8, São Paulo, nov. 1983.

A importância da exploração familiar camponesa na América Latina (1977). In: Coutinho, Carlos Nelson e Albuquerque, Beatriz D. de (orgs.). Agricultura, democracia e socialismo. Rio de Janeiro: Paz e Terra, 1988.

SANTOS, Raimundo. O pecebismo inconcluso. Escritos sobre ideias políticas. Seropédica: 1992; 1994.

Caio Prado Jr. e a cultura política brasileira. Rio de Janeiro: Mauad, 2001.

SILVA, José Graziano da. Por uma reforma agrária não essencialmente agrícola (1996). In: Santos, Raimundo e Costa, Luiz Flávio C. (orgs.). Política e reforma agrária, Rio de Janeiro: Mauad, 1998.
SODRÉ, Nelson Werneck. Formação histórica do Brasil. São Paulo: Brasiliense, 1962.

VIANNA, Luiz Werneck. Liberalismo e sindicato no Brasil. Rio de Janeiro: Paz e Terra, 1976.

O problema da cidadania na hora da transição democrática. Rio de Janeiro: Série Iuperj, 1983. 